\title{
Priorities for the Development of Regional Information Management Based on System Digitalization
}

\author{
Yuliia Kovalenko ${ }^{1}$, Oksana Zakharova ${ }^{2 *}$, , Oksana Yakusheva $^{2,3}$, Oleksandr Yakushever, \\ Daniil Hulak ${ }^{2,5}$ and Svitlana Kozlovska ${ }^{6}$ \\ ${ }^{1}$ Donetsk National Technical University, 2, Shibankova Square, Pokrovsk, Ukraine \\ ${ }^{2}$ Cherkasy State Technological University, 460, Shevchenko Blvd, Cherkasy, Ukraine \\ ${ }^{3}$ Individual-entrepreneur Yakusheva Oksana Viktorivna, 46/20, Microdistrict Lazurniy, Pokrovsk, \\ Ukraine \\ ${ }^{4}$ Individual-entrepreneur Yakushev Oleksandr Volodumurovich, 13, Tolstoy str, Pokrovsk, Ukraine \\ ${ }^{5}$ PJSC «Cherkasyoblenergo», Hoholya street, 285, Cherkasy, Ukraine \\ ${ }^{6}$ Rauf Ablyazov East European University, 16, Nechuy-Levitsky str., Cherkasy, Ukraine
}

\begin{abstract}
The article is devoted to the substantiation of regional information management development priorities based on the digitalisation system. The paper substantiates the sequence of managerial actions in the development of Ukraine's economic digitalisation, taking into account existing changes in regional management, outlining the accumulated potential of science and practice, forming compliance with global progress of digitalisation and requiring a scientifically sound platform for regional information management. The directions of digitalisation intensification and information management development in Ukraine are formulated. The expediency of creating a specialised automated information system, the purpose of which should be to assess regional economic processes and prospects for their development in terms of economic growth, is substantiated. Requirements to information support of administrative activity in the system of regional management are formulated. The main tasks of information management support for the achievement of regional information management efficiency are defined. Keywords: Regional information management, Digitalization, Information and communication technologies, Economy of Ukraine.
\end{abstract}

\section{Introduction}

Acceleration of scientific and technological progress, strict adherence to innovative development is promising area of science. It forms the foundation of a scientifically sound solution to the problems hindering the movement towards European integration, the information economy and the information society in Ukraine. Solving problems and systemic conflicts of managerial, economic, socio-cultural nature is a prerequisite and factor in

* Corresponding author: bonheur5576@gmail.com 
attracting breakthrough technologies and achieving the desired changes, compliance with the vectors of information progress, primarily to increase productivity; socialisation of the economy and its systemic cultural progress; introduction of innovative and informationintensive technologies.

With the use of information and communication technologies in all spheres of modern life, as well as with increasing quantity and quality of information, processing and assimilation of which is impossible without proper implementation of information technology, the question of forming a new, progressive vision of regional policy and regional governance. The formation of the information society requires a revision of state policy on regional development, development and implementation of state programs aimed at the priorities of information progress and digitisation of knowledge.

Society expects changes in the formats of the latest reforms, the continuation of the "old" reforms, the definition and strategic justification of growth points and vectors of priority movement. Modelling of the future is still active; processes have only just begun, but growth points have already been identified and the vector of the social economy and information society is emphasised. The scenarios of Ukraine's development focus on the systemic development of the IT sector, its state and multifaceted support; tax reform; mass privatisation; comprehensive de-shadowing of the economy.

\section{The sequence of management actions in the development of digitalisation of Ukraine's economy}

We will supplement and expand the vision of priorities for the development of Ukraine's economy based on systemic digitalisation through targeted processes and activities at the regional level and understanding the involvement of a full range of regional information management, vector for knowledge management in models of state, regional and sectoral management.

The phasing and scientific validity of such a movement is the primary interest of government and business, the need for time, an element of managerial progress. We recommend a sequence of management actions that consider existing changes, outline the accumulated potential of science and practice, form in line with global progress of digitalisation and require a science-based platform for knowledge management and regional information management.

The first stage. They define the role and place of regional information management in economic reform and compliance of the vector content of scientific provisions with the models of the information society; social, cluster and knowledge economy. The transition to the standards of the information economy, the mass phenomena of digitalisation are already actively taking place, the social economy and the knowledge economy appear to be developed models within the European space and need their optimal adaptation. The most significant and influencing the stimulation of the economy and society should be the transition to a cluster model (information-cluster; network-cluster) [1].

The second stage. Research and comprehensive analysis of changes in the economy of the Ukrainian regions in the direction of digitalisation. Independent analysis and identification of changes within the informatisation of government agencies and enterprises, industrial and market infrastructure; production modernisation; involvement and real efficiency of various information technologies; scale and comprehensiveness (territorial and sectoral) of modern information technologies.

Let's single out the changes that need their targeted research and will be recognised as key in further elaboration:

- determination of priorities, target vectors that correspond to the purpose of the trend of knowledge digitisation; 
- recognition of fundamental changes characteristic of the latest information systems (information technology) support emergence;

- assessment of the available information potential and trends of its changes;

- evaluation of supply and demand in the market of IT services and IT products;

- assessment of technological support (technology, innovation, technology maintenance);

- development of knowledge management tools and technologies.

The third stage. Interconnectedness and assessment of interdependent processes of complex regional informatisation and corresponding changes in the economy, social sphere. Based on the achieved level of informatisation and automation, there is a rapid introduction of intelligent technologies.

Examples of smart cities that are actively working become practical embodiments of the most modern intelligent technologies. Such examples exist in Ukraine to a small extent. The city of Kyiv positions already tested and implemented smart technologies - e-ticket; video surveillance of car traffic in real-time; medical information services, etc., already downloaded to the Kyiv Smart City application. Access to such information is centrally published on the nashkiev.ua portal.

The fourth stage. Independent research and comprehensive study of the Ukrainian cities digitalisation processes from the standpoint of the future role of growth points in all regions (diagnosis, monitoring). Definition of zones and spheres of competitive advantages information market, information services, the general process of regional digitalisation, the all-Ukrainian format of smartization of vital activity.

It should be noted that in Ukraine, the process of regions digitalisation is, relatively speaking, a "point". This means that computer and communication technology, telecommunications networks, databases and data banks, information technology, information systems and analytical centres of various levels, information technology products, systems of research institutions and training of highly qualified specialists first emerge and are implemented in large cities, and then diffusely spread into the region by district centres, etc. In addition, this process is more intense in regions with a high level of socio-economic development, thus causing the divergence of regions in the level of informatisation and further digitalisation in the form of intelligent technologies cooperation. Given that any process has limits of growth, sooner or later there will be a convergence of regions in terms of their informatisation, and hence in terms of information and technology support of the region's economy [2].

The processes of convergence and divergence manifest the informatisation intensification, the rapid advancement of smart technologies in the regions and the country as a whole, which covers all spheres of human life. Modern computer and telecommunication means are being introduced, computer networks are being laid, and databases are being created, the latest smart technologies of doing business are being formed, and the economy of information activity is developing significantly. At the same time, not all regions have the same opportunities to meet information needs based on the formation and use of information resources and modern technologies [3].

Fifth stage. Evaluation and study of regional issues of Ukrainian regions Internet coverage (target projects). Such research is systematically conducted by companies providing Internet services (PJSC "Ukrtelecom", PJSC "Datagroup", holding "Triolan", PJSC "Kyivstar", CC "Volya", PJSC "Vega", CC "Frigate", TeNet etc.).

Peculiarities of shifts in the regions of Ukraine covered by the Internet show an active growth in the number of users, the latest service technologies are being rapidly introduced. Regarding the territorial distribution, the most significant growth of Internet users is observed in the Central part of Ukraine - on average by $6.7 \%$ per year. In the Western region of the country, this figure is $4 \%$. Unfortunately, the problematic military-political situation in the 
country has led to an annual Internet users number reduction by $6.5 \%$ in the East and $7.2 \%$ in the South [4].

Topical issues of Internet services market development need independent research:

- commercialisation of Internet resources in the regions of Ukraine. This question is relevant from the standpoint of expanding the boundaries of regional information markets and determining the business potential operating in the information market (and not only Ukrainian);

- promotion of smartization technologies and gaining experience in the relevant implementation of services (transport, education, medicine, etc.);

- cybercrime assessment;

- technical and technological problems of network access by regions.

The sixth stage. Assessment of asymmetry in the development of digitalisation processes at the level of the regions of Ukraine. The most relevant and popular are the issues of determining asymmetry:

- between cities and rural regions to attract information resources to make management decisions;

- gap in the minimum and maximum indicators of quantitative and qualitative changes (services, online services);

- in assessing the quality of IT services by region (for example, comparing the capital with peripheral cities);

- between the most successful and least equipped technologies and tools for digitalisation of regions.

The seventh stage. Obtaining a generalised diagnosis of the regions of Ukraine according to the main parameters of digitalisation (based on the target comparison with the indicators of Kyiv; European, for example, Poland).

The eighth stage. Formation of the targeted policy of digitalisation development in the regions of Ukraine on the platform of involvement and implementation of mechanisms and technologies of regional information management. Formation of a knowledge management model of regional information management taking into account economic, technical and technological, social and cultural interests of the population and business, conformity to the general movement of information progress.

\section{Directions for intensifying the development of digitalisation and information management}

Comprehensive movement in the direction of these stages involves the involvement of a large amount of digitised information and the latest knowledge. First of all, this is official information published on the official web portal of the State Statistics Service of Ukraine (www.ukrstat.gov.ua) and the main statistical offices of the regions. IDI indices developed and calculated by international organisations are relevant in the research (United Nations eGovernment Readiness Index), IDI development index, network-ready index (NRI) and others. Only a comparison of data and results with world standards will provide an accurate picture of the promotion of integrated informatisation, digitalisation, e-government standards.

The driver, the main component of knowledge of regional information management and the corresponding transition to the targeted digitalisation model are information systems that ensure the transformation of information into solutions by the resource potential of government and various organisations, knowledge of people who operate and distribute information.

We recommend the initial vision of the classification of information technologies (applied), which are of strategic importance and form the potential for future deployment of 
regional information management from the standpoint of accumulation of information resources (systemic involvement of information potential) and accelerate digitisation in all areas of regional and sectoral management:

- types and areas of obtaining and selling information resources;

- location of productions, organisation of settlements, production processes;

- public service systems based on the involvement of smart technologies (utilities, health care, education, etc.);

- environmental control and monitoring systems (smart technologies - assessments, examinations, etc.);

- geoinformation support for decision making;

- sphere of organisation of public services (information consultations, provision of documents, organisation of control, etc.);

- attraction and use of intellectual and labour potential of territories;

- virtualisation and telecommunication support, communication and communication systems;

- the latest information technologies for business incubation - acceleration and virtualisation;

- decision support; development, implementation, control over various types of policy (social, demographic, environmental, cluster, support of small and medium business, financial, innovation and investment, etc.);

- security, risk assessment, conflict zones, etc.

Also, a priority vector and an urgent task of economic science in today's Ukrainian economy realities, socio-economic reforms are the development of mechanisms for information support of decisions on the region's development, made by the legislature and the executive.

To date, the Ukrainian public administration has recorded the presence of more than 300 state registers for the provision of state registration services. Such a fact should not exist from the standpoint of duplication of information, criminal concealment of information and other systemic violations, especially property rights.

A systematic study of the regulatory framework of regional informatisation and the practice of regional governance in Ukraine indicate an insufficient informatisation and implementation of new, advanced information technologies and information support in the management decision-making system. This hinders the formation and development of regions and the state in general, preventing the formation of adequate management infrastructure.

Insufficient development and lack of support for the methods and approaches implemented in the information resources management system is a conflicting issue in the recognised quality of informatisation of regional management. In addition, the process of introducing advanced information technologies in administrative management is constrained by the weak level of organisation of information flows, collection, processing, storage and provision of information. Ways and methods of formalising information in the modern management system may not always be applicable in the regional management system of socio-economic processes. At the same time, a significant role in regional management is played by information exchange, which forms a specific information space in a particular geographical region, within which all business entities perform their information functions [5].

The involvement of cloud technologies, which have already gained worldwide recognition, is of particular importance for Ukrainian regional management. Priorities for attracting cloud technologies should be recognised: statistical and analytical support; egovernment; communications of government, business and the population; remote provision 
of services; provision of educational services; cooperation with enterprises of the region and other areas.

The development of information management methodology and practice makes it possible to consider new independent areas of management related to information resource management, information processing, implementation and use of information technology in enterprises and organisations, recognition in the European information space and global markets of smart specialisation. The circulation of information between the elements of the system, the system as a whole and the environment is a prerequisite for effective, balanced, harmonious management in any field of activity. Thanks to information processes, given vectors of change, the system can carry out purposeful interaction with the external environment, coordinate the relationship of its components, direct their movement to a specific goal. The detailed data become management information if the consumer uses them in management processes directly before or after certain transformations. Thanks to management information systems, management data is transformed into management information, digitised and transparent, relevant to users' needs.

A separate area of information management development is the problem of providing managers with the necessary information for management decisions. The development of effective management decisions is based on competencies such as creativity, sociability, multiculturalism, communication, cooperation, critical thinking and in market conditions is primarily determined by objective, comprehensive, reliable information about existing processes.

One of the most important factors that should increase the efficiency of regional government in Ukraine is the introduction of information technology to change the nature of management work, strengthen the analytical and statistical component in the management decision-making process. Professional knowledge in regional management is marketing, project management, business administration, modelling and programming. At the same time, the following areas of involvement of advanced tools and technologies in practice should be considered priority and promising:

- development of fundamental information tools and information technologies (on platforms of cloud technologies, neural networks, geoinformation products, smart technologies);

- improvement and updating of operating systems;

- involvement of relevant programming languages;

- dissemination of technologies Data Mining, 3D printing, blockchain;

- attraction of information resources, automated programming, neurocomputations, clientserver architecture, geoinformation and other database and knowledge management systems;

- dissemination and activation of telecommunication, multimedia and text systems, expert systems;

- improvement of security and cryptosecurity technologies;

- formation of introductory applied IT (provide development and implementation of standard technologies and procedures for processing information resources; definition of approaches and methodological support on standard procedures for accumulation, systematisation and processing of information by types and industries).

\section{Creation of a specialised automated information system}

The effectiveness of the regional policy of socio-economic development of the region depends on the timeliness, reliability, completeness and objectivity of the information received, the efficiency of its processing and generation in the system of management decisions. These processes constitute a system of information support of the management 
mechanism with current development priorities, methods, principles of management, which are based on the results of scientific and technical information development, methods and ways of accumulation and processing of information. It is necessary to create an information system of regional management, which would provide the process of managing the region with quality and timely information during management decisions.

One of the ways to overcome this conflict situation is the introduction of a specialised automated information system. In this case, choosing a model of such a system, which will provide the maximum and fastest effect at the lowest cost, becomes especially important. The system's primary purpose is to assess regional economic processes and prospects for their development in terms of economic growth. Creating an information system of regional information management is information support of regional management, business projects, the ability to inform investors about the investment potential of regional enterprises, information and analytical support, covering various aspects of regional reproduction processes. The results of economic analysis and forecasting can also form the basis for regional economic development.

The primary purpose of the development and implementation of the information system is information and analytical support of the management process, which helps reduce uncertainty and risks when making strategic and tactical decisions $[6,7,8]$.

Requirements for information support of management activities in the regional management system also determine the unique, essential characteristics of information about the subjects of management to which it is intended. These features have their own theoretical and methodological basis, outline the formats of future development of this field of knowledge.

First, the information is intended for different management entities. Such information should be concise, diverse, relevant in content and as accessible as possible to a wide range of users.

Second, the information that enters the management system must be systematic, efficient, meaningful and objective. Due to limitations or bias, the essence of the management decision may be distorted; its effectiveness may be reduced after its adoption. In such cases, it is justified to use information from various sources to fully provide the authorities and eliminate the facts of failure or asymmetry in the information support.

Third, the information should be accompanied by targeted recommendations and relevant recommendations because, as practice shows, the management system always lacks unique and reference sources, integrated data (statistical collections, expert assessments, dictionaries, directories, geographic information resources, targeted innovativeapplications).

The functional part is always related to the model of the management system of a specific object; in our case, it is the implementation of programs and projects of regional development that are relevant and meet the needs of the time.

We recommend that this area include issues related to:

- nature management and resource balance;

- formation of a system of resettlement, migration flows;

- evaluation and involvement of labour potential;

- development of interregional communications, intersectoral complexes and production infrastructure;

- targeted regulation of cluster formation processes;

- improvement of socio-cultural infrastructure;

- administrative-territorial development;

- systematic assessment of the development and support of small and medium-sized businesses; 
- integration of government and business actions in the form of networks, technology parks, business incubators and accelerators, educational projects;

- targeted regulation of regional and sectoral markets.

We will give a brief description of the main elements of the information system of regional management, which are relevant in the formats of practical development and a further improvement in the knowledge system of regional information management, providing the involvement of knowledge management approaches [9-14].

Technical support - a set of technical means designed for the operation of the information system and relevant documentation for these means and technological processes.

Mathematical software is a set of mathematical methods, models, and algorithms for processing information used to solve problems and make management decisions. For instance, there is mathematic linear regression, which is widely spread in the use of researches, forecasting and development.

Statistical support is a set of statistical methods, models, and algorithms for processing information to create a management system.

The program software is a set of programs for implementing the goals and objectives of the information system, the normal functioning of a set of technical means.

Methodical and organisational support - a set of methods, tools and documents governing the interaction of information system personnel with technical means and with each other in the development and operation of the information system.

Legal support - a set of legal norms governing information systems' creation, legal status, and operation.

Information support of the management process is one of the functions of creating conditions for the effectiveness of management activities at all its levels: from an individual official to the highest public authorities. This function in the theory and practice of social systems management is called information and analytical support.

We recommend that the information support of the management process be effective to involve some requirements. Among them are:

- minimum information - provides for the restriction of collection and processing only those data (information), without which it is impossible to manage the object;

- optimal information - information meets the main requirements, comes high quality and on time.

Sufficiency of information - means that the information should give a comprehensive and complete picture of the operation of the object, as well as optimal or similar solutions. When determining the needs for certain types of information, we must first consider the importance of managing each type, the frequency of receipt, the relationship with other types of information.

The Ukrainian regional management system often lacks information because not all data included in the management system are helpful, presented in the proper form and meet the objectives of management. For example, some statistical reporting forms contain not so many news reports as reference and calculation indicators. There is no information on the state and quality characteristics of the business environment, cluster formation processes, the latest forms of business, renewal and modernisation of production.

As a result, there is a contradictory situation. When the management bodies are overloaded with generalised information on the economic development of the territory and economic agents, decisions are often made in conditions of uncertainty (conflict of information), which significantly reduces their quality.

One of the main requirements for the management process is to ensure the high reliability of the data used in decision-making processes. Without accurate information about the object of management, it is impossible to organise its work, use the most advanced management methods. 


\section{Conclusions}

Providing the necessary information to specialists at all levels has a positive effect on creating a rational, harmonised organisational structure of management and allows the application of new methods, increased productivity, and the overall level of management culture.

One of the main requirements for the management process is to ensure the high reliability of the data used in decision-making processes. Without accurate information about the object of management, it is impossible to organise its work, use the most advanced management methods.

At the regional level, the main tasks of management information support should be:

- creation of new generation regional management information systems (based on digitalisation tools and taking into account the best world experience);

- identifying the needs of all stakeholders in new information technologies and databases;

- development of standard projects and standards of information support of the regional management system;

- improvement of statistical reporting in the system of regional management (according to the latest standards of business evaluation, social sphere, information component of development);

- preparation of normative-legal acts on the issues of information support of the administrative system of regional administration bodies, in particular the system of protection against information threats.

The solution of the set tasks is possible due to the creation of the subsystem of information-analytical support, which should be aimed at high-quality management of socioeconomic processes to achieve stability, self-sufficiency, and ensuring normal living conditions of the region. The creation and further operation of the subsystem should be carried out taking into account modern requirements and technical and technological capabilities based on available means of processing, storage and provision of information, information technology and more.

The introduction of modern information technologies and improvement of informatisation of management processes can form a basis for growth of efficiency of administrative activity in the long run, strengthen competitive positions of regions, and provide a necessary level of information security. At the same time, one of the most critical factors of effective management is the use of information potential as a component of the socio-economic, information regional potential of Ukraine.

\section{References}

1. V. Bero, Yu. Chupailenko, Problems of Innovation and Investment Development, 5, 916 (2013)

2. I. Shevchuk, Information technologies in the regional economy: Theory and Practice of Implementation and Use, Monograph. (Lviv, NNVK "ATB", 2018)

3. Virtual Museum of Canada (VMC). 30.03.2011, http://www.museevirtuelvirtualmuseum.ca

4. O. Zinchenko, Formation of positive potential regions' image of Ukraine: Theory, Methodology, Practice, Monograph (Cherkasy, R. Ponomarenko edition, 2018)

5. Yu. Kovalenko, Herald of Donetsk State University of Management, 35, 33-38 (2018)

6. K. Beliakov, Informatization in Ukraine: problems of organisational, legal and scientific support, Monograph (Kyiv, KVIC, 2008) 
7. Yu. Kovalenko, Problems and features of regional information management development, Monograph (Cherkasy, R. Ponomarenko edition, 2018)

8. O. Zakharova, N. Podluzhna, O. Yakusheva, and O. Yakushev, Regional policy of advanced ICT in the minds of forming economy knowledge, in Proceedings of the 16th International Conference on ICT in Education, Research and Industrial Applications. Integration, Harmonisation and Knowledge Transfer, ICTERI, Kharkiv, Ukraine, 2740, 386-391 (2020)

9. I. Sotnyk, D. Hulak, O. Yakushev, O. Yakusheva, O.V. Prokopenko, and A. Yevdokymov, Polityka Energetyczna - Energy Policy Journal; 23(3), 147-164 (2020)

10. K. Wiig, Knowledge Management 20 Years After. The Evolution and Increasing Significance of Knowledge Management, http://www.krii.com/downloads/KM20 Years Later.pdf (2018)

11. Software and Information Technology Spotlight, https://www.selectusa.gov/softwareand-information-technology-services-industry-united-states (2018)

12. C.P. Francisco, D.V.J. Nilson, Journal of Technology Management \& Innovation. 3(4), 80-94 (2008)

13. M. Abbasi, P. Vassilopoulou, L. Stergioulas, Creative Industries Journal, 10(1),1-19 (2017)

14. C. Chapain, N. Clifton, and R.Comunian, City, Culture and Society, (5), 51-53 (2014) 